\title{
"Nacido en el país al amparo de la hidalga Nación Española". Los usos del factor racial en el control del poder local en Filipinas a finales del siglo XIX
}

\author{
por \\ Juan Antonio Inarejos \\ Instituto de Historia, CCHS-CSIC
}

\begin{abstract}
En el artículo se rastrean los usos de la raza y el mestizaje en el acceso y control del poder local en Filipinas durante la dominación colonial española. Se analiza cómo la raza determinó la ubicación de cada individuo dentro de la pirámide de poder de la colonia, categorías raciales que moldearon y quedaron solidificadas en la legislación y sirvieron para aquilatar privilegios y excepciones. Se indagan las dicotómicas estrategias desplegadas por las élites nativas en relación al poder local durante la segunda mitad del siglo XIX.
\end{abstract}

Palabras Clave: Filipinas; colonialismo; elecciones; poder local; élites indígenas; raza.

CUESTIÓN INTRODUCTORIA SOBRE LA ESTRUCTURACIÓN DEL PODER LOCAL FILIPINO

Las estructuras coloniales implantadas en Filipinas se basaron en la combinación de mecanismos de poder directos e indirectos y se organizaron en torno a unas relaciones de poder ancladas en categorías raciales. En efecto, la Recopilación de Indias y las Leyes Especiales regularon y consolidaron una estratificación social de las diferentes razas como forma de dominación en las posesiones asiáticas ${ }^{1}$. Esta realidad persistió durante la implantación del Estado liberal en España de modo que la nueva legislación ultramarina articuló una organización del archipiélago filipino a partir de la división es-

\footnotetext{
1 Alvarado, 2001.
} 
tablecida entre los sujetos de la colonia y los ciudadanos de la metrópoli². La Constitución de 1837 cercenó los plenos derechos de ciudadanía de los filipinos y les arrebató las aspiraciones de representación política despertadas por la Constitución imperial de Cádiz ${ }^{3}$.

Dentro de este andamiaje, las principalías indígenas fueron los únicos espacios de representación tangibles para las elites nativas. La regulación del poder municipal sufrió escasas modificaciones a lo largo de los cuatro siglos de dominación española tras la incorporación de las estructuras locales prehispánicas al armazón colonial. Los cargos de gobernadorcillo y cabezas de barangay -asimilables con salvedades a los alcaldes y concejales peninsularesfueron reservados por ley a los naturales y mestizos de sangley ${ }^{4}$. Los orígenes del cabeza de barangay se remontan a los jefes de los diferentes grupos territoriales y familiares prehispánicos homónimos. El barangay era un grupo de tributantes que podían vivir en diferentes barrios de una localidad al frente de los cuales se situó el cabeza de barangay. Un sorteo realizado entre los cabezas de barangay que formaban cada principalía designaba doce electores. Éstos y el gobernadorcillo saliente eran los trece encargados de elegir una terna formada por los tres individuos más votados. El resultado era elevado al Gobernador Civil, quien proponía al Gobernador General de Filipinas al individuo de esta terna que consideraba más apto, o bien decretaba, si procedía, la anulación de la votación tras sopesar los minuciosos informes elaborados sobre cada uno de los miembros de la terna por parte de la Guardia Civil, el administrador de Hacienda, el Juez de primera instancia y el párroco de la localidad.

En paralelo, los peninsulares monopolizaron los altos cargos de la administración colonial ${ }^{5}$. En comparación con el precedente americano, los mestizos españoles constituyeron un porcentaje muy reducido en relación a la pobla-

${ }^{2}$ Los peninsulares que se radicaron en las colonias perdieron derechos civiles, políticos y de representación, a pesar de que también fueron compensados con los beneficios derivados del statu quo colonial, como la propiedad esclavista en Cuba o la práctica patrimonialización de los puestos en la administración colonial en Filipinas; Fradera, 2008: 19-21.

3 Celdrán Ruano, 1994. Fradera, 2008: 9-30.

${ }^{4}$ Para profundizar en el origen -racista- del término mestizo y su aplicación a los mestizos de chino -también conocidos como mestizo de sangley- y español, véanse los clásicos trabajos de Wickberg, 2000; 1964: 62-100. Para una comparación con el mestizaje americano, Gruzinsky, 2000.

${ }^{5}$ Véase un análisis de la bibliografía referente a la organización del poder político, religioso y socioeconómico en el archipiélago, en los trabajos recogidos en la obra editada por María Dolores Elizalde, 2009a, aspectos a su vez sintetizados en el capítulo elaborado por la editora de la obra, 2009b: 45-78. 
ción total del archipiélago ${ }^{6}$. En la legislación del Estado liberal español, el recuerdo del protagonismo desempeñado por los criollos en las independencias latinoamericanas pesó como una losa en la organización del poder colonial y en los intentos por acotar la pujanza de este «peligroso» grupo social ${ }^{7}$. Esta realidad explica el menor impacto de reclamaciones mestizas en Filipinas si se comparan con las planteadas por los mestizos de otros escenarios coloniales europeos en Asia ${ }^{8}$. En definitiva, en el caso del Estado español también existió una relación contradictoria y asimétrica en la definición de los contenidos de la ciudadanía para los metropolitanos, por un lado, y para los habitantes de las colonias, por otro. Cerrada la puerta de la representación parlamentaria, los nativos dirigieron las riendas de los municipios.

En el caso filipino se asistió a dos procesos contrapuestos en relación al poder local. Y éste es el objeto de análisis de este artículo, el uso ambivalente del factor racial por parte de las elites locales para evitar o monopolizar el desempeño del poder municipal. En efecto, en aquellas principalías donde los cargos municipales fueron indeseados y concebidos como una carga se recurrió a las categorías raciales para intentar sortear estos cargos. Se usaron dos vías. Por un lado las elites locales intentaron lograr la exención que gozaban los españoles. Por otro, los principales intentaron acabar con este privilegio para que los españoles asumieran estos cargos y compartiesen las responsabilidades de gobierno. Por el contrario, en aquellas principalías donde los cargos municipales sí despertaron interés, se asistió a una estrategia defensiva de las élites que

${ }^{6}$ Sinibaldo de Mas, en su Informe sobre el Estado de las Islas Filipinas en 1842, estipuló, como condición para preservar la colonia, la reducción de la población criolla «al menor número posible (...) porque entre la población blanca nacida en el país, se forma un interés local opuesto al de la metrópoli, el cual empieza por crear un descontento y termina por sugerir el deseo de la independencia»; vol. 3, capítulo "Política interna": 2. Este informe es desmenuzado en Fradera, 2009: 135. Y Blanco, 2009: 87. Los mestizos españoles ascendieron a una cifra estimada en 20.000 individuos en 1842, frente a los 3500 españoles nacidos en Filipinas y unos 1.500 peninsulares sobre una población total de unos cinco millones, según los datos arrojados por Sinibaldo de Mas en el capítulo que dedicó al análisis de la población, vol. 1: 136. Ferdinand Blumentritt subrayó con agudeza en la década de los Ochenta las razones que podían llevar a estos «criollos» hacia el descontento, como la monopolización de cargos por parte de los peninsulares: «de allí viene el que sean precisamente los criollos los más sospechosos para los españoles»; 1889: 15-16. A la altura de 1893, Manila, capital que concentró el mayor número de peninsulares, gozaba de una población de 4.189 españoles peninsulares y 3.849 mestizos de español; Elizalde, 1998: 322. Para el resto de provincias véanse los trabajos recogidos por Doeppers y Xenos, 1998.

7 Para abordar el protagonismo de los criollos en la independencia de las colonias continentales americanas me remito a los recientes balances de Sánchez Andrés, 2011. Y Chust, 2013.

${ }^{8}$ El caso de los numerosos mestizos franceses de Indochina ha sido estudiado en profundidad por Saada, 2007. 
utilizaron este sistema racial en beneficio propio para evitar las usurpaciones ilegales de estos puestos por parte de los peninsulares y mestizos españoles.

\section{LAS VÍAS PARA EVADIR EL PODER LOCAL O LOS CONATOS DE ACCESO A LOS PRIVILEGIOS DE LOS PENINSULARES}

Y cuáles han sido las consecuencias de este abandono completo respecto al municipio indígena? Que los cargos concejiles han ido cayendo en el mayor desprecio; que el cargo de gobernadorcillo se ha hecho aborrecible y no hay ninguna persona pudiente que lo resista, porque comprende que se ha de ver en la alternativa, o de hacer gastos de su propio peculio, o de consentir y complicarse en abusos que resiste su conciencia y que le ponen a merced de sus enemigos. Las clases acomodadas se han ido separando de ese movimiento y alternativa del tribunal; no quieren, ni toman parte en las elecciones; y si para algo ponen en juego toda su influencia, es para evitar el ser elegidos ${ }^{9}$.

A la altura de 1871 Manuel Azcárraga levantó acta de la desazón interiorizada por las elites indígenas a la hora de ejercer el poder local y escribió precisamente una obra para exigir la necesidad de una reorganización del municipio indígena. Había sido Gobernador civil de Manila y, sin duda, esta experiencia fue clave para perfilar y concretar sus impresiones. Por eso argumentó con rotundidad su diagnóstico, válido para la capital y algunas de las ciudades y provincias, pero no aplicable al conjunto del archipiélago, según él mismo se encargó de matizar a partir de sus experiencias como Alcalde mayor de Cagayán y Bulacán ${ }^{10}$.

A partir de esta realidad, Xavier Huetz de Lemps ha sistematizado las principales líneas de fractura que mediatizaron el debate que trajo a colación Azcárraga en torno al interés o desinterés por el ejercicio del poder local en Filipinas. En efecto, las investigaciones de Huetz ratifican las aseveraciones realizadas por Azcárraga para el caso de Manila -a excepción de los cargos de las comunidades de chinos-, e introdujo importantes puntualizaciones sobre las restantes provincias, sus niveles de riqueza y en función de la variable campo-ciudad ${ }^{11}$. En aquellas principalías marcadas por el desinterés resulta

\footnotetext{
9 Azcárraga y Palmero, 1871: 17.

10 Manuel Azcárrraga aseveró que en Cagayán y La Isabela, donde los gobernadorcillos y cabezas de barangay gozaron de una gratificación por la recogida del tabaco, los cargos sí fueron deseados; 1871: 19.

${ }^{11}$ Huetz de Lemps, 1997: 436-437. Estas cuestiones también fueron señaladas por Sánchez Gómez, 1989: 57. Batangas es una de las provincias mejor conocidas. En esta circunscripción un tercio de las élites económicas locales que lideraron los partidos o facciones que se dispu-
} 
bien conocido el manido recurso de los principales a las alegaciones de enfermedad como chivo expiatorio para desprenderse de estos cargos una vez fueron designados ${ }^{12}$. Sin embargo, no ha gozado de la misma atención el uso de las diferencias raciales a la hora de intentar evadir las responsabilidades de gobierno. Sin duda, fue un recurso menos transitado pero cualitativamente decisivo para reconstruir el andamiaje racial de la administración colonial.

En concreto, valga el ejemplo de las reivindicaciones que siguieron a la celebración de las elecciones en el arrabal de Binondo (Manila) el 14 de abril de 1883, reclamaciones que aportan sugerentes elementos para desvelar estas maniobras ${ }^{13}$. Mariano Barrera Limjap solicitó a las autoridades españolas ser eximido del cargo de gobernadorcillo de mestizos de sangley de este barrio después de haber sido elegido en primer lugar de la terna ${ }^{14}$. El interés de esta demanda, una más de la secular cascada de renuncias que siguió a cada nueva elección, radicó en las excepcionales razones esgrimidas para justificar la exención. Concretamente blandió el estatus de su padre para intentar beneficiarse de los privilegios que gozaban españoles y mestizos de españoles para sortear las responsabilidades de gobierno municipal. Mariano era hijo de Joaquín Barrera Limjap, chino que había logrado la naturalización española de $4^{\text {a }}$ clase mediante un Real Decreto de 7 de junio de $1878^{15}$. El cambio

taron el poder en las localidades de la provincia entre 1887 y 1894 ostentaron directamente el cargo de gobernadorcillo, mientras que los restantes fueron controlados por testaferros, clientes o lugartenientes, según May, 1987: 30-52; 1991: 33. Llegué a similares conclusiones a partir del estudio de la principalía batangueña de Balayán. Inarejos Muñoz, 2011: 742-761. El interés reinante en Pampanga, la península de Bikol, la provincia de Cagayán, la de Cavite y la de La Unión; Larkin, 1972: 91-94. Owen, 1974: 304 y 309-311. De Jesús, 1978: 154155. Borromeo-Buehler, 1985: 74. Inarejos Muñoz, 2012: 199-224; respectivamente; contrasta con la notoria desafección mostrada en Nueva Écija, Rajal y Larre, 1889: 312; o en Cebú, marcada por la dicotomía entre la atonía experimentada en la capital y el interés explicitado en las zonas rurales de esta circunscripción; Fenner, 1985: 155-157.

${ }^{12}$ A través de la falsificación de los certificados médicos, expedidos en su gran mayoría sin el previo reconocimiento médico, fraude que intentó combatir Weyler. Sánchez Gómez, 1991: 365.

${ }_{13}$ Philippine National Archives (Manila) (PNA), Serie Elecciones de Gobernadorcillos (SEG), Manila, legajo 136, rollo 6577. Se ha consultado la copia de esta documentación albergada en el Centro de Ciencias Sociales y Humanas del CSIC (Madrid). Para evitar la reiteración de citas, cuando no se mencione el origen específico de la fuente, se hace referencia a este legajo.

${ }_{14}$ Para profundizar en la compleja organización política, social y económica de los chinos y mestizos de chinos, Wickberg, 2000; 1964: 62-100. Wilson, 2004. Chu, 2010. Gil, 2011.

${ }^{15}$ Expediente de naturalización del chino Joaquín Barrera Lin Yapco, 1887-1880, Archivo Histórico Nacional, Madrid (AHN), legajo 5346, exp. 21. Las fuentes presentan distintas formas de denominar a esta persona: Limjap, Lin Jap, Lin Japco, Lina Japco o Lin Japo, aunque la 
de estatus paterno dentro del escalafón social de la colonia supuso su baja taxonómica como chino. Bajo su óptica, esta permuta de la condición paterna también implicó su cese como mestizo de sangley y su alta como mestizo de español: había pasado de ser hijo de chino a ser hijo de español. Barrera se parapetó en el artículo $7^{\circ}$ del Decreto de 5 de octubre de 1847 que fijó como cualidades imprescindibles para ser elegido gobernadorcillo la condición de natural o mestizo de sangley. Para apuntalar su argumentación en torno a la legitimidad de su exención alegó el principio incontestable de que los hijos asimilaban la condición del padre.

Los razonamientos expuestos por Mariano Barrera fueron sometidos a revisión por las autoridades coloniales, apresuradas a desmontar la «confusión de principios» interiorizada por el recurrente. Para el Negociado de Administración Civil ${ }^{16}$, el padre era «de nación chino», casado en dominio español -Filipinas- con una natural y vecina de Binondo. Por extensión, su hijo Mariano Barrera fue, antes que su padre, español en categoría de mestizo chino, «porque español es todo aquel que nazca en los dominios españoles». No obstante, Filipinas se regía por Leyes Especiales y no se aceptó el principio invocado por Mariano Barrera, ante la imposibilidad de atestiguar haber permanecido siempre sujeto a la condición de su padre. Es decir, era imposible que Mariano Barrera corroborase su clasificación y encuadramiento como chino, al igual que su padre, hasta que éste último obtuvo la naturalización como español. En suma, se subrayó la evidencia de que Mariano Barrera había sido considerado un mestizo de sangley ${ }^{17}$. La doctrina al respecto era tajante:

más utilizada es la primera. El expediente ofrece sugerentes datos para reconstruir su trayectoria biográfica desde su llegada a Manila el 1 de noviembre de 1847, como su bautismo (fechado el 15 de diciembre de 1852, en la parroquia de Santa Cruz de Manila, apadrinado por Fulgencio Barrera, español europeo y Capitán de Marina Sutil y Doña Joaquina Caldes de Barrera, de quienes tomó su apellido), su enlace con una mestiza de sangley, su descendencia o su fortuna derivada de los importantes negocios que consiguió amasar durante estas tres décadas (valorada en unos 200.000 pesos). Estos méritos, junto a su regular situación con Hacienda y su buena conducta, le permitieron cumplir los requisitos que las leyes exigían para optar a la carta de naturaleza (según las Reales Cédulas de 10 de agosto de 1815 y de 18 de octubre de 1817). Gozó con informes favorables del Ayuntamiento de Manila, del Consejo de Administración y con el visto bueno del Gobernador de Manila. El 2 de enero de 1880 juró y renunció a todo pabellón extranjero.

${ }^{16}$ El funcionamiento y organización de la administración colonial filipina, en Huetz de Lemps, 2006.

${ }^{17}$ La permeabilidad y maleabilidad de esta identidad posibilitó que años más tarde fuese considerado como un chino: «Mariano Limjap (Lin He), son of a chino father and a mestizo mother, was also a critical financier of Aguinaldo's rebellion. While technically a mestizo, the fluidity of ethnic identities in the colonial Philippines allowed Limjap to deploy numerous identities. While he was born locally, many of his business dealings were with chinos and thus 
El hijo sigue la condición del padre cuando aquella es heredada, cuando es condición de sangre y no se oponen a ello las leyes del país como sucede en el presente caso, que el hijo no nació con la condición de chino que tiene su padre. Para que el hijo siga la condición graciosamente adquirida por el padre, es preciso que en la concesión se haga declaración expresa de que el beneficio se extienda a los descendientes del agraciado como habría sucedido quizá a instancia propia si el interesado hubiera nacido en el país de su padre en vez de haber visto la luz en Manila ${ }^{18}$.

A modo aclaratorio, el dictamen fue acompañado de un sucinto repaso de la estratificación social colonial ${ }^{19}$, dividida en cinco clases de españoles con una terminología diferenciada: los «españoles peninsulares» (procedentes de la metrópoli); los «españoles filipinos» o criollos (nacidos en Filipinas pero de padres de «pura raza española»); los «mestizos españoles» (de padre español y madre india); los «mestizos de sangley» (de padres chino e india) y los naturales o «aborígenes» ${ }^{20}$. Según corroboró esta autoridad, «todos sin duda, son españoles; todos están regidos por unas mismas leyes generales, con las variantes apropiadas a la condición de raza». El criterio racial, reconocido de forma explícita como el factor determinante de la ubicación socioeconómica de cada individuo en la sociedad filipina, circunscribió «la superioridad de raza» a peninsulares y a sus hijos nacidos en el archipiélago. Los mestizos españoles, a pesar de que disfrutaban de prerrogativas que les distinguían de los indios, figuraron en los padrones tributarios levantados por los frailes, aunque no al mismo nivel que los naturales ${ }^{21}$. Desde la Dirección General de Administración Civil se utilizó este argumento para invalidar la reivindicación

much of his support for the cause of Philippine independence was probably drawn from the Chinese economy», Wilson, 2004: 159, 162-163. Véase también Chu, 2002a: 44-74.

18 PNA, SEG, Manila, legajo 136, rollo 6577.

${ }_{19}$ Catalogada por Paul Kramer como una sociedad pluriestamental donde la naturalización y jerarquización de la sangre delimitaron los derechos políticos, categorías sociales que sufrieron escasas modificaciones durante el dominio americano, Kramer, 2006: 35-86; 2011: 125-144. Véase también Camacho, 2002: 43-74; y Sánchez Gómez, 2003: 21.

${ }^{20}$ La reducida emigración peninsular fue abrumadoramente de carácter masculino. El papel de la mujer en la sociedad colonial, y el surgimiento de una nueva identidad y sexualidad femenina impulsada por los ilustrados filipinos, en Reyes, 2008. Para un análisis comparativo de la instrumentalización de la raza y la sexualidad femenina en otros escenarios coloniales europeos en Asia, Stoler, 1995. Clancy-Smith y Gouda, 1998.

${ }^{21}$ Concretamente como contribuyentes con el diezmo de reserva y sanctorum. Las distintas categorías contributivas, también ancladas en categorías raciales, y las reformas tributarias emprendidas entre mediados del siglo XVIII y finales del siglo XIX, son deslindadas en Fradera, 2005: 486-532. Las críticas de los religiosos a la reorganización hacendística de 1883 y la consiguiente reformulación de los tributos de naturales y mestizos, equiparación que bajo su óptica suponía una seria amenaza por la equiparación de derechos, en Sánchez Gómez, 2003: 293. 
del recurrente, puesto que los mestizos españoles no seguían la condición del padre como había sugerido Mariano Barrera para respaldar sus aspiraciones:

Los hijos no son libres de nacer bajo la nacionalidad que les plazca y por esa razón siguen la de sus padres y tienen que estar sujetos a las leyes y disposiciones del país en que nacen, cuya nacionalidad llevan mientras no llega la edad de la emancipación, en cuya época pueden variarla; pero sí les es potestativo en tiempo en sujetarse a apartarse de una nueva nacionalidad adoptada por los padres ${ }^{22}$.

Bajo esta meridiana perspectiva, la naturalización en un país distinto al del nacimiento era adquirida «graciosamente», es decir, no suponía la variación de raza o condición porque no variaba la naturaleza del individuo ${ }^{23}$. Condición y calidad, por extensión, no eran sinónimos, sino que existía una importante disociación a tener en cuenta, en palabras textuales, «con la condición se nace y la calidad se adquiere». Desde este punto de vista, la calidad era concebida como un distintivo de nobleza, una cualidad moral indivisible que los padres únicamente podían legar a uno de sus hijos. En el caso de que esa cualidad fuese exclusivamente vitalicia acababa con el fallecimiento del individuo.

Este fue el caso del recurrente. La concesión a su padre del estatus de español de $4^{\text {a }}$ clase no vino acompañada de una declaración expresa de su carácter hereditario. Una circunstancia a la que añadieron un agravante, la superior condición del hijo respecto a su padre, puesto que había nacido como español en calidad de mestizo de sangley, con derechos y prerrogativas que el padre no tenía. En suma, esta autoridad puso de relieve la sima abierta respecto a la condición de su padre. Si hubiese heredado la condición paterna habría sido considerado como chino y no como mestizo de chino, cuando «el interesado

22 PNA, SEG, Manila, legajo 136, rollo 6577.

${ }^{23}$ Confirmando los procesos de ascenso social, y sus correspondientes límites, señalados por Wickberg, 2000: 7-8: «This formalization and legalization of cultural differences as social differences did not result in a strictly fragmented society. Individuals within each group readily interacted with those of other groups and, the Spanish group excepted, individuals could change status and move from group to group». Hay que precisar que este autor denomina a los peninsulares con el término «Spanish». Este tipo de naturalizaciones tuvieron un carácter excepcional y debieron quedar circunscritas a personalidades con un alto nivel económico, como fue el caso de Joaquín Limjap. Wickberg interpretó estas iniciativas como una estrategia del régimen colonial para atraerse a los chinos más prominentes a través de la concesión de prerrogativas exclusivas de españoles y peninsulares; 2000: 155-156. En esta misma dirección, y subrayando la similitud de esta estrategia a la desplegada por los británicos en Singapur o los holandeses en Java, Wilson, 2004: 57; autor que también incide en las percepciones de los chinos que obtuvieron la naturalización española, quienes se vieron como servidores de dos imperios sin que hubiese contradicción en ello; 139. Resulta tortuoso evaluar el alcance de esta estrategia, que traspasa los objetivos de este artículo, fracasada en el caso de la familia Barrera por su ya mencionado apoyo a la rebelión de Emilio Aguinaldo. 
no ha perdido ni podido perder la condición natural de mestizo de sangley». La demanda de exención solicitada había quedado seriamente deslavazada.

La sentencia del Negociado respaldó las aspiraciones expresadas por un grupo de principales del gremio de mestizos del arrabal de Binondo que también habían elevado una exposición al Gobernador General de Filipinas con el objetivo de presionar para que Mariano Barrera fuese designado gobernadorcillo. En su escrito incidieron en algunos de los argumentos planteados por la administración colonial, y de forma particular en la imposibilidad de transmitir de padre a hijo un privilegio otorgado a un ciudadano extranjero a título exclusivamente personal:

De admitir lo contrario, Excmo. Señor, había que admitir el absurdo de que un hijo de Filipinas, nacido en este país bajo la honrosa dominación de España, tiene aún necesidad, para que sea español tal naturalizado, de obtener carta de naturalización, la cual repugna, no sólo a las Constituciones fundamentales de aquella nación magnánima y generosa, sino a sus nobles sentimientos, y a la levantada idea que guió a sus esforzados hijos al conquistar para su Corona a Filipinas, de hacerla solidaria de su honor y su grandeza, dándole generosamente su idioma, sus leyes, sus costumbres y hasta su preclara sangre ${ }^{24}$.

La «preclara sangre» aludida en la sumisa exposición se erigió en uno de los elementos que sustentaron el régimen de privilegios y control social establecido en aras de los «nobles sentimientos» con que se adornó el poder colonial. Ante todo, se basó en un vínculo sanguíneo cuyos privilegios quedaban diluidos en la segunda generación mestiza. En segundo lugar, los principales enfatizaron la inexistencia de impedimentos que inhabilitasen tanto al padre como al hijo a la hora de ejercer cargos concejiles. Para respaldar esta aseveración arguyeron la existencia en la legislación que regía el archipiélago de un privilegio por el cual un extranjero naturalizado podía detentar estos empleos en los dominios españoles ${ }^{25}$. Una excepcionalidad que no afectaba al hijo, nacido en Filipinas y de madre natural, considerada por las leyes como española a efectos civiles.

24 PNA, SEG, Manila, legajo 136, rollo 6577.

25 Argumento que fue acompañado de un nuevo preámbulo retórico sumiso y adulatorio: «merced a los nobles sentimientos de España, que quiere demostrar su clara hidalguía a los que, haciendo abdicación en aras del sacrificio de su estado civil, se acogen a su augusta bandera para disfrutar de la libertad armonizada con la garantía de las leyes en sus Constituciones políticas, bajo los sacrosantos lemas de Religión, Patria y Rey». La omnipresencia de este lenguaje racista y clasista constituyó otro de los instrumentos utilizados por los colonizadores para marcar distancias con los colonizados en términos de prestigio y dignidad. Una estrategia retórica similar adoptaron los franceses en Indochina, Saada, 2007: 55-56. 
En tercer lugar los principales esgrimieron otro argumento relacionado con la excepcionalidad que regía en la organización del poder local en Manila ${ }^{26}$. Los demandantes recordaron que «individuos de raza española pura, que son mil veces de mejor condición que los naturalizados, y son más acreedores a excepciones y privilegios», desempeñaban en la capital cargos concejiles. Los puestos de alcalde y regidor del ayuntamiento de Manila eran copados por españoles o mestizos de español, cargos que equipararon a los de gobernadorcillo de gremios en los arrabales de esta ciudad, «pues estos no son más que pequeños ayuntamientos, asimilados a aquél» ${ }^{27}$. En este sentido subrayaron que ambas autoridades compartían prerrogativas, como las funciones de policía y ornato público, una razón más para poner de relieve la idoneidad de Barrera para el cargo que rehusaba. En la exposición se hizo hincapié en la denominación de pedáneo detentada por el gobernadorcillo del arrabal de Binondo, categoría que lo convertía en subalterno de las disposiciones que emanasen del Gobernador Civil, de los jueces de primera instancia y de los jefes económicos de la provincia. Es decir, no se trataba de una etiqueta meramente nominativa.

La única excepción que atesoró el cargo de gobernadorcillo de sangleyes estuvo relacionada con el elevado y creciente número de individuos englobados en un gremio que no tenía Cónsul que les representase, como sí ocurrió con el resto de extranjeros ${ }^{28}$. En relación a las restantes atribuciones del cargo de gobernadorcillo alegaron que era una institución «esencialmente española, creada por asimilación al cargo de Juez de paz en la península, exclusivamente para Filipinas en atención a su anómala manera de ser» ${ }^{29}$, ¿Anómala manera de ser o anómala manera de ser gobernados por Leyes Especiales?

Por lo tanto, si en Manila los mestizos españoles eran designados gobernadorcillos, los demandantes se preguntaron por qué no habrían de serlo también los naturalizados o hijos de naturalizados, en el caso de que esta cualidad fuese una excepción. Para apuntalar esta reivindicación trajeron a colación lo sucedido en el arrabal de San José, donde el último gobernadorcillo había sido un mestizo de español que había formado parte de numerosas ternas. Pero también echaron mano de la legislación reguladora, donde no se explicitó como impedimento que el candidato fuese hijo de español naturalizado.

26 Véase Huetz, 1997: 422-423.

27 La compleja organización municipal de Manila, en Huetz, 1998a: 28-48; 1998b: 381-428.

${ }^{28}$ El tortuoso proceso que llevó a la comunidad china de Filipinas a obtener representación consular durante el tramo final del dominio español, en la figura de Carlos Palanca Chen Quianshan, es analizado en Wilson, 2004: 111-139.

${ }^{29}$ Más detalles acerca del origen de este cargo, en Phelan, 1959: 124-125. Hidalgo Nuchera, 1995. 
Como último argumento realizaron una interpretación forzada y sesgada de la legislación, concretamente de las cualidades necesarias para ser elector y elegido recogidas en el Decreto de 1848. Sostuvieron la inexistencia en el articulado de una mención expresa a la condición de mestizo español, ni como tacha ni como excepción, y esgrimieron una máxima: cuando la ley no distinguía era regla general no introducir la excepción. Una interpretación interesada que obvió el explícito y excluyente listón racial establecido: «ser natural o mestizo de sangley» ${ }^{30}$. En última instancia, los demandantes argumentaron: si la condición de español naturalizado fuese admitida como excepción habría que admitirse que esta cualidad era indigna para el puesto de gobernadorcillo o bien que el propio cargo implicaba «cierta...bajeza de dignidad, lo cual jamás se puede permitir que se diga de esa institución, en honra y prestigio de la grande Nación Española». De forma sutil, y a pesar que de que no hizo una mención explícita en la legislación a esta categoría como factor de exclusión, la protesta hizo una inequívoca referencia y reconocimiento de los estigmas asociados a determinadas categorías raciales y al propio cargo de gobernadorcillo, designado bajo un término despectivo que no fue sustituido hasta la reforma de 1893 que aspiró a revalorizar sus funciones y significado ${ }^{31}$.

Finalmente, la Dirección General de Administración Civil, a pesar de aceptar la doctrina del Negociado que había decretado la capacidad de Mariano Barrera de ostentar el cargo de gobernadorcillo, propuso al elegido en segundo lugar de la terna, Vicente Oligario. En las elecciones celebradas el 14 de abril de 1883 Oligario había obtenido seis votos frente a los diez que recibió Mariano Limjap. Los informes emitidos por el párroco, el Jefe de la Guardia Civil y el Gobernador Civil de la provincia, sin embargo, habían favorecido al primer aspirante de la terna ${ }^{32}$. Sus antecedentes y conducta recibieron el

${ }^{30}$ Requisitos que no fueron una excepción para las específicas elecciones de gobernadorcillos del gremio de sangleyes. El artículo $9^{\circ}$ del Decreto de 1848 rezó: «En los pueblos donde los mestizos de sangley, por su crecido número, tienen gremio separado del de los naturales, se celebrarán las elecciones de Gobernadorcillos y demás oficiales de justicia del suyo con entera sujeción a lo dispuesto en los artículos anteriores; entendiéndose esto mismo en la parte que pueda tener aplicación para las elecciones de sangleyes en la provincia de Tondo, donde está concentrado todo su número.», en Rodríguez Bérriz, 1887, vol. 3: 52.

31 Sustituido por el de Capitán Municipal, Marimón, 1994: 94-138. Manuel Azcárraga, consciente de la trascendencia que desempeñó el honor en la sociedad colonial, ya había abogado dos décadas antes la sustitución de este término en su proyecto de reforma del municipio indígena: «el nombre mismo de gobernadorcillo, entienden que les rebaja, como que, por estar en diminutivo, parece que tiene a deprimir a la persona que lo ejerce y realmente este funcionario no está respetado», Azcárraga, 1871: 18.

${ }^{32}$ Para profundizar en el sistema de elección y las ternas, entre una amplia nómina, Bankoff, 1992: 679-700. 
beneplácito de las autoridades, quienes ensalzaron su actividad profesional como propietario de varias embarcaciones y de un importante comercio en Binondo, negocios que reconocieron su «honradez y formalidad» ${ }^{33}$. También hablaba bien castellano, al igual que el segundo aspirante de la terna, con quien compartió otra trascendental cualidad: su «buena posición». La acomodada posición económica de Oligario pudo ser la razón última de su designación, harto valorada por las autoridades coloniales, pese a contar con la incompatibilidad de ser un «empedernido» aficionado al juego ${ }^{34}$. El Negociado tuvo que elegir entre una posible negligencia en la recaudación de impuestos ${ }^{35}$, marcada por el explícito desinterés de Mariano Barrera en ostentar el cargo, y la fijación de Oligario por las cartas, cuyas deudas podían poner en entredicho su solvencia. Se decantó por el segundo.

Por el contrario, frente a la opinión del Negociado, la perversa afición por los naipes de Oligario llevó al Gobernador Civil de la provincia a decantarse por Mariano Limjap, aunque no fue la única causa. La autoridad provincial había realizado pesquisas sobre la condición tributaria de la familia Limjap para intentar esclarecer su estatus. El Gobernador Civil había recibido de la Administración central de impuestos directos de Filipinas una sugerente cer-

${ }^{33}$ Más detalles de las actividades económicas de la familia Barrera Limjap, en Wickberg, 2000: 87. Una fortuna que no menguó durante la época americana: «When Yanq Shiqi, viceminister of the chamber's imperial sponsor, the Nonggong Shangbu, visited the islands in November 1907, the Chamber provided a lavish reception at the mansion of local millionaire Mariano Limjap at a cost of U. S. \$6,000», Wilson, 2004: 178-179. Chu, 2002b: 351-360; 2010.

${ }^{34} \mathrm{El}$ artículo $4^{\circ}$ de la legislación rezaba sobre las cualidades que debían reunir electores y elegibles: «no ser de los que en sus casas acostumbran a tener en sus casas juegos prohibidos, o de los que hayan sido penados por reincidencia en este detestable vicio», Rodríguez Bérriz, 1887, tomo 3: 48.

${ }^{35}$ La diligencia y cumplimiento de las obligaciones recaudatorias de los gobernadorcillos fue una cualidad decisiva por las autoridades coloniales a la hora de seleccionar a las élites nativas. Unos años más tarde, el 27 de septiembre de 1887, Mariano Barrera Limjap fue gratificado junto a otro gobernadorcillo con la Cruz de Isabel la Católica a propuesta del Gobernador Civil de Manila por su diligencia recaudatoria al frente del gremio de mestizos de Binondo, el mismo cargo que había intentado esquivar con anterioridad: «No solamente han prestado su concurso a todos cuantos servicios se le han encomendado, sino que en la recaudación del impuesto provincial y cédulas personales han sido tantos y tan generosos sus comportamientos que en más de una ocasión su peculio particular ha suplido los cargos de muchos cabezas de barangay y de muchos de sus convecinos. Como se trata de dos personas que además de su prestigio gozan de buena posición social por cuanto D. José Guevara es un rico propietario y agricultor en su pueblo y D. Mariano Limjap pertenece al comercio de esta capital, tengo la horna de someter...para que sean significados con la cruz sencilla de la Real y distinguida de Isabel la Católica.», Propuesto para Cruz de Isabel la Católica a José Guevara. Concedida a Mariano Linjap, 1887-1889, AHN, legajo 5289, expediente 28. 
tificación. Según un Decreto de 19 de octubre de 1878, Joaquín Limjap había sido exceptuado de las contribuciones a las que estaban sujetos los chinos tras haber obtenido la naturalización española, exención que se hizo extensiva a su hijo Mariano. En virtud de esta orden, Mariano Barrera pasó a figurar en los padrones contributivos como mestizo de español ${ }^{36}$, según se lo hizo saber el gobernadorcillo de mestizos de Binondo al Gobernador civil en respuesta a una requisitoria de la autoridad provincial.

En suma, los derechos políticos y tributarios, aunque anclados ambos en categorías raciales, habían quedado disociados. La distinción entre condición y calidad afloró de nuevo. A efectos políticos, Mariano Barrera era un mestizo de sangley, mientras que a efectos tributarios era un mestizo de español. El Negociado hizo valer la condición sobre la calidad, enfatizada por el Gobernador civil, argumento que llevó a la Dirección General de Administración Civil a respaldar la doctrina del primero, centrada en evitar una extensión de los privilegios de los peninsulares. No resulta casual que la Dirección de Administración y Fomento, apenas concedida la nacionalidad a Mariano Barrera Limjap, propusiese a la sección de Ultramar la supresión de la Real Cédula de naturalizaciones en todas o en determinadas provincias de Ultramar ${ }^{37}$.

La cerrazón en la concesión de privilegios a mestizos y naturales, con el trasfondo del precedente americano, constituyó una de las señas de identidad de la administración española en Filipinas. Las instituciones gubernativas admitieron otras vías para sortear el desempeño de cargos públicos, pero los criterios raciales se mantuvieron incólumes hasta el final de la dominación como uno de los puntales de la segregación orquestada en la «Perla de Oriente».

\section{LAS CARGAS ANEJAS AL PODER LOCAL Y LOS INTENTOS DE DISOLUCIÓN DE LAS EXENCIONES}

Las tentativas de las élites nativas por evadir las responsabilidades de gobierno municipal también pergeñaron el despliegue de estrategias colectivas $\mathrm{u}$ holistas, orientadas a la equiparación de obligaciones y derechos entre todas las categorías raciales en el acceso y ejercicio del poder local. La protagoni-

\footnotetext{
${ }^{36}$ En virtud de una orden del Administrador de Hacienda pública de esta provincia de 5 de julio de 1879 .

${ }_{37}$ Expediente de naturalización del chino Joaquín Barrera Lin Yapco, 1887-1880, AHN, legajo 5346, exp. 21. La sección de Ultramar respondió que no entendía el propósito y alcance de la reforma ni a qué provincias de Ultramar sería aplicable.
} 
zada por un grupo de cabezas de barangay de Cavite constituye un ejemplo acabado $^{38}$.

El 8 de febrero de 1892 un grupo de principales de Cavite elevó al Gobernador General de Filipinas una sugerente exposición donde se reclamó la eliminación del tamiz racial para que los peninsulares pudiesen ocupar los cargos de gobernadorcillo y cabeza de barangay, puestos reservados exclusivamente a los naturales y mestizos de sangley. Los demandantes argumentaron su petición alegando la decadencia que se había apoderado de este puerto desde que en 1884 había sido suprimida la fábrica de puros ${ }^{39}$. El incremento de la emigración había sido una de las consecuencias más palpables de este cierre, corriente migratoria que también había sido favorecida por la disminución del trabajo en el arsenal, el otro gran motor económico de la localidad. Estos procesos habían originado una supuesta escasez de individuos naturales «idóneos» para ocupar los cargos concejiles. En la exposición se hizo una referencia explícita a la capacidad económica que debían reunir los aspirantes a ocupar estos cargos «para bien del erario», cualidad muy apreciada por las autoridades coloniales españolas por las funciones recaudatorias delegadas a estos cargos. No resulta baladí que ésta fuese precisamente una de las vitolas distintivas de los mestizos españoles que vivían en Cavite, argumento que sirvió a los demandantes para respaldar sus aspiraciones:

siendo estos últimos en mejor posición y bien acomodados... creemos que sí, que con sus bienes conocidos serán mejores guardadores de la recaudación y hevitarán (sic) no cabe la menor duda rezagos de los del género que ocasionen perjuicios irreparables al estado, como repetidas veces ha habido y pueden haberse más si se continúa encomendando estos cargos a individuos jornaleros ${ }^{40}$.

Para reforzar sus planteamientos adujeron que mestizos españoles ocupaban cargos de alguaciles o mandatarios de tribunales en otros pueblos como San Roque (provincia de Cavite), puestos de menor relevancia que los de cabeza de barangay o gobernadorcillo. También se recordó cómo algunos de los privilegios que habían gozado los mestizos españoles, como la exención de prestar servicios militares, personales, municipales y concejiles, supuestamente habían sido suprimidos en 1877. En el terreno hacendístico, se trajo a colación la entrada en vigor de la unificación de las tasas y la abolición de la separación existente entre mestizos de español y sangley, refundidas en una

${ }^{38} S E G$, PNA, Cavite, legajo 65, rollo 6419. Entre los firmantes figuraron Juan Díaz, Casimiro Díaz, Máximo Antonio, Andrés San Agustín, Benito San Agustín, Florentino San Agustín, Manuel Carlos y Eduardo de los Santos.

39 Sobre el monopolio del tabaco, consultar De Jesús, 1980. Fradera, 2005: 439-533.

40 SEG, PNA, Cavite, legajo 65, rollo 6419. 
única categoría de naturales con la implantación de la cédula personal ${ }^{41}$. Los demandantes solicitaron hacer extensiva esta unificación al ejercicio de los cargos concejiles y otorgar a mestizos españoles avecindados la posibilidad de que ostentasen puestos municipales, en aras de la grandilocuente aspiración «del bienestar de la localidad».

En su trayecto administrativo, la exposición llegó a manos del Gobernador Político-militar de Cavite. Cayetano Vázquez y Más subrayó algunos de los argumentos planteados en el escrito elevado por los principales y aportó nuevos detalles del tejido social de la ciudad portuaria. Según su testimonio, el individuo que no gozaba de un puesto en la administración (ya fuese en la Armada, en el Ejército o en las demás dependencias del Estado) pertenecía a la «clase obrera», a excepción de un grupo de propietarios y algunos comerciantes e industriales, tanto peninsulares como insulares y chinos. Reconoció que los escasos elementos de riqueza que existían en la ciudad más allá del arsenal estaban en manos de unos cuantos mestizos españoles de «buena o mediana posición», colectivo que podía servir de garantía para cubrir con solvencia las ocho cabecerías existentes. De esta forma se evitaría que los cargos fuesen a parar a personas sin bienes e insolventes sin capacidad para adelantar fondos, evitar retrasos o hacer frente a posibles deudas.

El Gobernador Político-militar respaldó el «fin laudable» la propuesta, aunque desmontó el argumento de la equiparación tributaria esgrimido en el escrito y disoció la reformulación hacendística de la vigencia del privilegio de exención de los cargos concejiles. El secular reflujo de la brecha establecida entre derechos y obligaciones. Cayetano Vázquez y Mas también levantó acta de la indiferencia que despertaron estos cargos por «vejatoria y perjudicial como hoy por regla general sucede», cuando antaño naturales y mestizos coparon la representación de los pueblos, «distinción que tanto se complacían en alcanzar» ${ }^{42}$. Esta desazón permitió al jefe provincial justificar las reformas realizadas para atajar esta deriva y la necesidad de afrontar este problema en los debates que en ese momento estaban siendo abordados en torno a la organización municipal -y que cristalizaron en la reforma impulsada por Maura en 1893-43.

${ }^{41}$ En 1880 fue suprimida la distinción legal entre mestizos de sangley e indios, Wilson, 2004: 75. El impuesto de «cédula personal», creado en 1884 con carácter de documento de seguridad pública e identidad, aglutinó los anteriores tributos personales. Los agentes y mecanismos recaudatorios del tributo personal puestos en marcha por la administración colonial son detenidamente analizados en Fradera, 1999: 133-190.

${ }^{42}$ Afirmación que corrobora en Cavite la ya señalada dicotomía campo-ciudad en el interésdesinterés por controlar los cargos de gobernadorcillo, Borromeo-Buehler, 1985: 74.

43 En detalle, Marimón, 1994: 94-138. 
La administración de Hacienda aportó nuevos mimbres al debate. Concretamente trajo a colación una resolución de la Intendencia general de 1884 que había resuelto un contencioso similar planteado por el Alcalde mayor de Bataan, a la sazón Gobernador Civil de esta provincia. El dictamen había sentado jurisprudencia y estableció con rotundidad la exención que gozaban los mestizos españoles a la hora de ocupar los cargos de cabeza de barangay, «expresando ser justo y legal se reconozca ese privilegio a los que descienden de los descubridores y dominadores de estas Islas». La firme postura del responsable de Hacienda entró en colusión con la deriva aperturista planteada por el Gobernador-Político militar, dilecto a que los descendientes de los conquistadores aludidos en el fragmento anterior pudiesen desempeñar cargos concejiles -en sintonía con la exposición elevada-. Hacienda se decantó por la subsistencia de este privilegio al menos hasta que tomasen cuerpo las reformas que estaban siendo estudiadas, mencionadas de forma explícita en la recomendación que elevó ante Manila.

El Gobernador General de Filipinas, tras escuchar las diversas opiniones de los diferentes eslabones administrativos, cortó de raíz las aspiraciones planteadas por los cabezas de barangay de Cavite. No obstante, unos meses más tarde, Eulogio Despujol fue el encargado de aplicar la nueva reforma municipal impulsada por Maura que posibilitó la participación de las clases más pudientes en la elección de gobernadorcillos. Concretamente en función de una taxonomía económica, a través de la categoría de mayores contribuyentes (a quienes se reservaron tres de los doce electores designados para elegir al gobernadorcillo), y no como mestizos de español. Ambas cualidades, por otro lado, estrechamente imbricadas, según corrobora una de las resoluciones aclaratorias que acompañaron al citado Decreto de 1893: «la circunstancia de ser españoles filipinos los mayores contribuyentes, no es obstáculo a que gocen de los privilegios que como tales les concede el R. D. de 19 de mayo último, relativo al nuevo régimen municipal» ${ }^{44}$. El privilegio al que se refería no era otro que la persistencia en la nueva legislación del tamiz racial para ostentar los cargos de gobernadorcillo y cabeza de barangay (ser natural o mestizo de sangley). Las anteriores demandas y presiones que habían reclamado la eliminación de estas barreras no fueron atendidas, pues la posibilidad de incorporar a los mestizos a los órganos de gobierno municipal quedó circunscrita a su

${ }^{44}$ Fragmento extraído de la Resolución referente a la consulta elevada a la Dirección General de la Administración Civil, por el Gobernador de Leyte, acerca de si los mayores contribuyentes españoles filipinos, pueden intervenir en las elecciones para constituir los Tribunales municipales (Dirección General de Administración Civil de Filipinas, Sección de Gobernación), en "El municipio filipino", colección de El Faro administrativo, 1894, tomo I: 68. 
cooptación como meros electores. Una muestra más del escaso alcance de la reforma de 1893 y de la pervivencia de las cribas raciales hasta el final de la dominación española ${ }^{45}$.

\section{EL MANEJO DE LAS BARRERAS RACIALES COMO MECANISMO DE DEFENSA DE LAS ÉLITES NATIVAS}

En el extremo opuesto, las élites nativas también utilizaron los inamovibles criterios raciales para defender sus espacios de poder en los únicos eslabones de la administración colonial a los que tuvieron acceso. A diferencia de la apatía o desinterés que explicitaron los principales por controlar las principalías de grandes ciudades como Manila, motivadas por una mayor altura de miras o las pesadas cargas anejas a los cargos de gobernadorcillo y cabeza de barangay, en otras zonas del archipiélago más alejadas de los principales centros decisorios las élites locales sí explicitaron el deseo de controlar el poder municipal. Una buena muestra de este interés que despertaron radicó en las usurpaciones ilegales de estos cargos, reservados a naturales y sangleyes, protagonizadas por peninsulares y mestizos españoles y las iracundas reacciones desatadas entre las elites nativas en defensa de sus parcelas de poder.

El 16 de junio de 1890 un grupo de principales del pueblo de Legazpi (provincia de Albay) elevaron una instancia ante el Gobernador General de Filipinas en protesta por la elección de Pedro Morales, mestizo español, en el primer puesto de la terna para gobernadorcillo de la localidad ${ }^{46}$. Los denunciantes, amparados en la legislación, subrayaron su incapacidad para ostentar el mando local. Esta misma tacha supuestamente ya le había inhabilitado en 1887 cuando había sido propuesto en el segundo lugar de otra terna elegida con el mismo objetivo. El Gobernador Civil de Albay abrió un expediente informativo que puso en entredicho los argumentos de la denuncia. Esta autoridad demostró que Pedro Morales no era mestizo español sino hijo de mestizo español. En la copia de la partida bautismal solicitada al párroco de Albay se corroboró que Pedro Morales, nacido el 2 de diciembre de 1849 en esta localidad, era nieto del peninsular Esteban Morales e hijo de Pablo

\footnotetext{
${ }^{45}$ Novedad que supuso un intento de las autoridades coloniales de integrar en la estructura de poder municipal a la pujante burguesía. En cierta medida, y aunque no abolió los listones raciales, redujo las seculares presiones sobre los testaferros al propiciar la participación directa en las elecciones de los principales propietarios.

${ }^{46} S E G$, PNA, Provincia de Albay, legajo 9, rollo 6446. Los principales fueron Domingo Ortigas, Santiago Bajaro y Juan Domínguez.
} 
Morales, mestizo español, y de Apolonia Santa Ana, natural del barangay de Santos Inocentes.

Pedro Morales fue suspendido de forma temporal del cargo de gobernadorcillo el 8 de agosto de 1890, pero no a causa de la incompatibilidad racial, sino por faltas cometidas durante el ejercicio de sus funciones, castigadas con una suspensión transitoria (concretamente por el manido fraude en la redención en metálico de las prestaciones de trabajo personal ${ }^{47}$. La incapacidad racial para dirigir la principalía quedó diluida para los hijos de los mestizos de español, equiparados por tanto a los naturales. Cuestión aparte fue la elevada consideración social que ostentaron los hijos de mestizo español, cuyo estatus generó dudas y problemas a la hora de ubicarlos en la sociedad colonial ${ }^{48}$. Las protestas de los principales de Legazpi constituyeron un ejemplo acabado de esta confusión, pero también de la observancia de los criterios raciales como mecanismo de defensa de las élites nativas para evitar intromisiones en sus parcelas de poder.

Menos dudas generaron las irregularidades que tuvieron lugar durante las elecciones celebradas el 23 de noviembre de 1894 en la principalía de San Isidro de Tubao, en la provincia de La Unión ${ }^{49}$. Fueron orquestadas por la clientela de un peninsular, Santiago González, y su hijo, Carlos González, mestizo de español. Concretamente intentaron hacerse con la vara de gobernadorcillo pese a conocer su incompatibilidad para acceder a este cargo por su condición racial. Las elecciones a gobernadorcillo estuvieron mediatizadas por una amplia nómina de fraudes que desvirtuaron el resultado electoral y obligaron a repetir las votaciones hasta en cuatro ocasiones tras las constantes denuncias y anulaciones. Entre las corruptelas desplegadas destacaron la asistencia del gobernador civil a las votaciones para coaccionar a los electores y favorecer al mestizo español, la amenaza de apertura de procesos judiciales, la negativa a presentar escritos de protesta en el acta electoral, la destitución de cabezas de barangay o los sobornos. A pesar de su gravedad, las acusaciones anteriores no fueron la causa última que decidió a las autoridades coloniales a declarar la nulidad de las votaciones ${ }^{50}$. La principal razón estribó en el incumplimiento

47 Prestaciones obligatorias de carácter feudal basadas en trabajos en obras públicas, infraestructuras, etc... que continuaron vigentes a lo largo del siglo XIX, aunque progresivamente reducidos o redimidos en metálico, de las que quedaron exentos los peninsulares, Sánchez Gómez, 1991: 324-352; 2000: 577-599.

${ }^{48}$ Con la excepción de los frailes, que los vieron como una amenaza para su dominio por su elevada posición y su manejo de ambas lenguas, Sánchez Gómez, 2003: 295.

49 SEG, PNA, provincia de La Unión, legajo 112, rollo 6443.

${ }^{50} \mathrm{La}$ opacidad y ocultamiento de las prácticas corruptas fue catalogada por Xavier Huetz de Lemps como un «arma de control colonial», 2009: 143-156. 
de los requisitos legales para desempeñar el puesto, infracción que había sido denunciada por un grupo de principales que apoyaron al candidato opositor. En su exposición se escudaron en la nueva legislación aprobada por Maura, normativa que mantuvo el requisito de ser natural o mestizo de sangley para ostentar los cargos de capitán municipal. Carlos González no cumplía con esta condición. Su padre era Felipe Santiago González, un español europeo (de Zaragoza), y su madre, María Merced Fontanilla, era una nativa natural de Agoo, la localidad matriz de San Isidro de Tubao. Había quedado acreditado que Carlos González era un mestizo de español. Por ende, era inhábil para desempeñar el cargo de capitán municipal, pero también para ostentar el puesto de cabeza de barangay como había venido desempeñado de forma fraudulenta durante los últimos cuatro años.

Las autoridades de Manila se apresuraron a corroborar la verosimilitud las acusaciones de los denunciantes. La partida bautismal de Carlos González, remitida por el vicario provincial de La Unión, certificó su condición mestiza y constituyó el detonante que llevó a la Dirección general de Administración Civil a invalidar el proceso electivo. El estatus de «español filipino» de Carlos González, y no la amplia nómina de corruptelas perpetradas ${ }^{51}$, fue la causa esgrimida por las autoridades para anular las votaciones: «por desconocer que el citado González tenía la condición personal de ser español filipino y no la de indígena o sangley que la ley determina para servir dicho cargo» ${ }^{52}$. En las pesquisas complementarias que investigaron las restantes denuncias de fraude también quedaron al descubierto las ilegalidades en las que incurrió el zaragozano Felipe Santiago González. El padre del candidato ostentaba el cargo de juez de paz de Tubao y había ejercido como elector en la votación que había dado la victoria a su hijo. Había violado la normativa dos veces, como juez y como elector. Su condición de europeo entró en colusión los artículos que reservaron los cargos municipales a los naturales y le impedían tomar parte en el proceso electoral o votar a un familiar. Felipe Santiago González, retratado en los informe elevados por el párroco como poseedor de «considerables bienes de fortuna», podría haber tomado parte en el proceso electivo en calidad de mayor contribuyente si el candidato no hubiese sido un familiar.

Ésta fue una de las novedades que había introducido la reforma proyectada por Maura y que precisamente a través de este nuevo canal participativo tam-

51 Objeto de análisis en Inarejos Muñoz, 2012: 199-224.

${ }^{52}$ La utilización del término «español filipino» es confuso en algunas fuentes decimonónicas. En unas ocasiones se utiliza para designar a los nacidos en Filipinas de padres peninsulares, como hace Sinibaldo de Mas, y en otras para designar los mestizos españoles, como ocurre con esta fuente. 
bién aspiró a institucionalizar o mitigar la fraudulenta injerencia que sufrieron las élites nativas en sus espacios de poder a manos de españoles y mestizos de españoles, corroborada por los clarividentes casos anteriores. Pero también para atraerse a estos sectores donde estaba calando el discurso nacionalista: filipinos españoles, mestizos españoles de mayor antigüedad y los más numerosos mestizos de Sangley, los principales soportes de la incipiente burguesía colonial ${ }^{53}$.

\section{A MODO DE CONCLUSIÓN}

La raza determinó la ubicación de cada individuo dentro de la pirámide de poder de la colonia. De este modo, el factor racial en sus diversas modalidades indígenas moldeó la realidad del poder y se plasmó en una legislación que consolidó privilegios y excepciones. No obstante, la realidad del mestizaje diluyó estas rígidas fronteras establecidas y reformuló la adquisición y pérdida de privilegios respecto a los peninsulares. El mestizo español de segunda generación perdió los privilegios de los peninsulares, con el subsiguiente agravio comparativo, pero adquirió la prerrogativa de acceder a las instancias de poder municipal de forma legal. Por extensión, raza y mestizaje fueron dos categorías explotadas a la hora de acceder y controlar el poder local. Frente a la rígida parcelación establecida entre las distintas razas (peninsulares, nativos, chinos o sangleyes), los mestizos españoles -categoría en algunos casos de difícil clasificación y determinación práctica-, se erigió en una condición decisiva para controlar el poder municipal. Se trató de una confusión favorecida por la distancia establecida entre el discurso y la práctica social.

En teoría los mestizos españoles de primera generación, conocidos como «filipinos españoles», fueron equiparados en derechos a los «europeos»o «peninsulares». Los indios o mestizos de sangley fueron vetados para ejercer derechos políticos de ciudadanía o ingresar en las escalas superiores de la administración colonial. Más aún, en la práctica los escasos espacios de poder que les fueron reservados también fueron usurpados por peninsulares y mestizos españoles gracias a la anuencia de la administración colonial y la confusión generada por esta categoría racial.

En suma, la instrumentalización de las diferencias raciales a la hora de intentar evadir las responsabilidades de gobierno, en aquellas zonas donde fueron consideradas como una carga, se erigió en un recurso poco transitado

53 Según apostilló Elizalde, 2002: 123-142. Unas pujantes fuerzas sociales, y las consecuentes políticas imperiales que intentaron subordinarlas, que constituyen dos de los aspectos que reclaman nuevos estudios, bajo la óptica de Fradera, 2005: 682. También Elizalde, 2009b: 68. 
pero cualitativamente decisivo para reconstruir el andamiaje racial de la administración colonial. Los derechos políticos y tributarios, aunque anclados ambos en categorías raciales, fueron disociados para aquilatar los argumentos gubernativos frente a las constantes y crecientes reclamaciones que demandaron una extensión de los privilegios monopolizados por peninsulares y mestizos españoles. Esta cerrazón en la concesión de privilegios a mestizos de sangley y naturales constituyó una de las señas de identidad de la administración española en Filipinas, marcada inexorablemente por el precedente americano. La corroída burocracia colonial fue permisiva con otras vías para sortear el desempeño de cargos públicos, pero los criterios raciales se mantuvieron incólumes hasta el final de la dominación como uno de los puntales de la administración implantada en el archipiélago asiático. Una amplia gama de fraudes electorales fue consentida, pero las maniobras que afectaron a la arquitectura racial fueron segadas de raíz por las implicaciones que conllevaron. Eran órdagos o aspiraciones de máximos que la estructura colonial no podía atender sin demoler el edificio de privilegios construido durante siglos.

Los privilegios inherentes a la sangre persistieron en la postrera legislación que mantuvo el tamiz racial para ostentar los cargos municipales. Las demandas y presiones que reclamaron la eliminación de estas barreras no fueron atendidas. La posibilidad de incorporar a los mestizos de español a los órganos de gobierno municipal quedó circunscrita a su cooptación como meros electores. Una muestra más del escaso alcance de la reforma maurista y de la pervivencia de las cribas raciales hasta el final de la presencia española.

En el extremo opuesto, las élites nativas también utilizaron los criterios raciales para defender sus espacios de poder en los únicos eslabones de la administración colonial a los que tuvieron acceso. Esta fue una de las novedades que había introducido la reforma de 1893 y que permitió institucionalizar o mitigar la fraudulenta injerencia de los españoles y mestizos de españoles en los espacios de poder propios de las élites nativas. Los españoles y mestizos de españoles adquirieron la posibilidad de participar directamente en el gobierno municipal a través de una categoría económica y no racial, la de mayores contribuyentes. No obstante, este nuevo canal participativo no consiguió satisfacer plenamente las aspiraciones de los sectores que abogaron por romper y acabar con un régimen de privilegios políticos y tributarios varados en categorías raciales.

\section{BiBLIOGRAFÍA}

Alvarado, Javier, Constitucionalismo y codificación en las provincias de Ultramar. La supervivencia del Antiguo Régimen en la España del siglo XIX, Madrid, CEPC, 2001. 
Azcárraga y Palmero, Manuel de, La reforma del municipio indígena en Filipinas, Madrid, J. Noguera, 1871.

Bankoff, Greg, "Big Fish in Small Ponds: The Exercise of Power in a Nineteenthcentury Philippine Municipality", Modern Asian Studies, 26/4 (Cambridge, 1992): 679-700.

Blanco, John David, Frontier Constitutions. Christianity and Colonial Empire in the Nineteenth-Century Philippines, Berkeley, University of California Press, 2009.

Blumentritt, Ferdinand, Consideraciones acerca de la actual situación política en Filipinas, Barcelona, Imprenta Ibérica de Francisco Fossas, 1889.

Borromeo-Buehler, Soledad, "The Inquilinos of Cavite: A Social Class in NineteenthCentury Philippines", Journal of Southeast Asian Studies, XVI/1 (Singapore, 1985): 69-98.

Camacho, Marya Svetlana T., "Race and Culture in Spanish and American Colonial Policies", Hazel M. McFerson (ed.), Mixed Blessing: The Impact of the American Colonial Experience on Politics and Society in the Philippines, Westport, Greenwood Press, 2002: 43-74.

Celdrán Ruano, Julia, Instituciones Hispanofilipinas del siglo XIX, Madrid, MAPFRE, 1994.

Chu, Richard, "Rethinking the Chinese Mestizos of the Philippines", Shen Yuangfang and Penny Edwards (eds.), Beyond China: Migrating Identities, Canberra, Coombs Publishing/Australian National University, 2002a: 44-74.

Chu, Richard, “The 'Chinese' and 'Mestizos' of the Philippines: Towards a New Interpretation.”, Philippine Studies, 50/3 (2002b): 327-369.

Chu, Richard, Chinese and Chinese Mestizos of Manila, Leiden/Boston, Brill, 2010.

Chust, Manuel y Frasquet, Ivana, Tiempos de revolución. Comprender las independencia iberoamericanas, Madrid, Mapfre/Taurus, 2013.

Clancy-Smith, Julia y Gouda, Frances (eds.), Domesticating the empire: race, gender and family life in French and Dutch colonialism, Charlottesville, University Press of Virginia, 1998.

De Jesús, Carlos Edilberto, “Gobernadorcillo Elections in Cagayan", Philippine Studies, 26/1 (Manila, 1978): 142-156.

De Jesús, Carlos Edilberto, The Tobacco Monopoly in the Philippines. Bureaucratic Enterprise and Social Change, 1776-1880, Quezon City, Ateneo de Manila University Press, 1980.

"El municipio filipino", El Faro administrativo, Manila, Imprenta de D. J. Atayde y Compañía, 1894, tomo I.

Doeppers, Daniel F. y Xenos, Peter (eds.), Population and History. The Demographic Origins of the Modern Philippines, Manila/Madison, Ateneo de Manila/University of Wisconsin, 1998. 
Elizalde Pérez-Grueso, María Dolores, "Filipinas, fin de siglo: imágenes y realidad", Revista de Indias, 213 (Madrid, 1998): 307-339.

Elizalde Pérez-Grueso, María Dolores (ed.), Repensar Filipinas. Política, Identidad $y$ Religión en la construcción de la nación filipina, Barcelona, Bellaterra, 2009a.

Elizalde Pérez-Grueso, María Dolores, "Sentido y rentabilidad. Filipinas en el marco del Imperio Español”, María Dolores Elizalde Pérez-Grueso (ed.), Repensar Filipinas. Política, Identidad y Religión en la construcción de la nación filipina, Barcelona, Bellaterra, 2009b: 45-78.

Fenner, Bruce Leonard, Cebu under the Spanish Flag 1521-1896. An Economic and Social History, Ceby City, San Carlos Publications/University of San Carlos, 1985.

Fradera, Josep María, Filipinas, la colonia más peculiar. La hacienda pública en la definición de la política colonial, 1762-1868, Madrid, CSIC, 1999.

Fradera, Josep María, Colonias para después de un imperio, Barcelona, Bellaterra, 2005.

Fradera, Josep María, "La nación desde los márgenes (Ciudadanía y formas de exclusión en los imperios)", Illes i Imperis, 10/11 (Barcelona, 2008): 9-30.

Fradera, Josep María, "Reformar o abandonar. Una relectura del conocido como Informe secreto de Sinibald de Mas sobre Filipinas", María Dolores Elizalde PérezGrueso (ed.), Repensar Filipinas. Política, Identidad y Religión en la construcción de la nación filipina, Barcelona, Bellaterra, 2009: 121-141.

Gil, Juan, Los chinos en Manila, siglos XVI y XVII, Lisboa, Centro Científico e Cultural de Macau, 2011.

Gruzinsky, Serge, El pensamiento mestizo, Barcelona, Paidós, 2000.

Hidalgo Nuchera, Patricio, Encomienda, tributo y trabajo en Filipinas (1570-1608), Madrid, Ediciones Polifemo/Universidad Autónoma de Madrid, 1995.

Huetz de Lemps, Xavier, "La crise de la commune indigène a Manille au XIXe siècle”, El Lejano Oriente Español: Filipinas (siglo XIX), Sevilla, Cátedra General Castaños, 1997: 419-442.

Huetz de Lemps, Xavier, "Nommer la ville: les usages et les enjeux du toponyme «Manila» au XIXe. Siècle.”, Genèses, 33 (Paris, 1998a): 28-48.

Huetz de Lemps, Xavier, “Territorio y urbanismo en las Islas Filipinas en el entorno de 1898", Ciudad y Territorio, XXX/116 (Madrid, 1998b): 381-428.

Huetz de Lemps, Xavier, L'Archipel des épices La corruption de l'Administration espagnole aux Philippines (fin XVIIIe-fin XIXe Siècle), Madrid, Casa de Velázquez, 2006.

Huetz de Lemps, Xavier, "Una escuela colonial de disimulación", María Dolores Elizalde Pérez-Grueso (ed.), Repensar Filipinas. Política, Identidad y Religión en la construcción de la nación filipina, Barcelona, Bellaterra, 2009: 143-156. 
Inarejos Muñoz, Juan Antonio, "Reclutar caciques. La selección de las élites coloniales filipinas a finales del siglo XIX", Hispania, 71/239 (Madrid, septiembre-diciembre 2011): 741-762.

Inarejos Muñoz, Juan Antonio, "La influencia moral en Asia. Práctica política y corrupción electoral en Filipinas durante la dominación colonial española", Anuario de Estudios Hispanoamericanos, 69/1 (Sevilla, 2012): 199-224.

Kramer, Paul, The Blood of Government. Race, Empire the United States and the Philippines, Chapel Hill, The University of North Carolina Press, 2006.

Kramer, Paul, "Historias transimperiales. Raíces españolas del estado colonial estadounidense en Filipinas", María Dolores Elizalde Pérez-Grueso y Josep María Delgado (eds.), Filipinas, un país entre dos imperios, Barcelona, Bellaterra, 2011, pp. 125-144.

Larkin, John A., The Pampangans. Colonial Society in a Philippine Province, Berkeley, University of California Press, 1972.

Mas, Sinibaldo de, Informe sobre el Estado de las Islas Filipinas en 1842, Madrid, Imprenta Sancho, 1843, 3 vols.

May, Glenn Anthony, "Civic Ritual and Political Reality: Municipal Elections in the Late-19th-Century Philippines", A past recovered, Quezon City, New Day, 1987: 30-52.

May, Glenn Anthony, Battle for Batangas: a Philippine province at war, New Haven, Yale University Press, 1991.

Marimón, Antoni, La política colonial d'Antoni Maura. Les colònies espanyoles de Cuba, Puerto Rico i les Filipines a finals del segle XIX, Palma, Edicions Documenta Balear, 1994.

Owen, Norman G., "The Principalia in Philippine History: Kabilokan, 1790-1898”, Philippine Studies, 22 (Manila, 1974): 297-324.

Phelan, John, The Hispanization of the Philippines. Spanish Aims and Filipino Responses, 1565-1700, The University of Wisconsin Press, Madison, 1959.

Rajal y Larre, Joaquín,'Memoria acerca de la provincia de Nueva Écija", Boletín de la Sociedad Geográfica, XXVII (Madrid, 1889): 290-359.

Reyes, Raquel, Love, Passion and Patriotism. Sexuality and the Philippine Propaganda Movement, 1882-1892, Singapore/Seattle, Nus Press/University of Washigton Press, 2008.

Rodríguez Bérriz, Miguel, Diccionario de la Administración de Filipinas, Manila, Establecimiento tipográfico-litográfico de M. Pérez (hijo), 1887, tomo 3.

Saada, Emmanuelle, Les enfants de la colonie. Les métis de l'Empire français entre sujétion et citoyenneté, Paris, Éditions La Découverte, 2007. 
Sánchez Andrés, Agustín y Straka, Tomas (comps.), Las Independencias de Iberoamérica, Caracas, Konrad Adenauer Stifnung-UCAB- Fundación Empresas Polar, 2011.

Sánchez Gómez, Luis Ángel, "Elecciones locales indígenas en Filipinas durante la etapa hispánica", Florentino Rodao (ed.), Estudios sobre Filipinas y las Islas del Pacífico, Madrid, Asociación Española de Estudios del Pacífico, 1989: 53-61.

Sánchez Gómez, Luis Ángel, Las principalías indígenas y la administración española en Filipinas, Madrid, Universidad Complutense, 1991.

Sánchez Gómez, Luis Ángel, "Los debates sobre la regulación de la prestación personal en Filipinas durante el siglo XIX", Anuario de Estudios Americanos, 57 (Sevilla, 2000): 577-599.

Sánchez Gómez, Luis Ángel, Un imperio en la vitrina. El colonialismo español en el Pacífico y la Exposición de Filipinas de 1887, Madrid, CSIC, 2003.

Stoler, Ann Laure, Races and the education of desire. Foucault's history of sexuality and the colonial order of things, Durham/London, Duke University Press, 1995.

Wickberg, Edgar, "The Chinese Mestizo in Philippine History." Journal of Southeast Asian History, V/1 (Cambridge/Singapore, 1964): 62-100.

Wickberg, Edgar, The Chinese in Philippine life (1850-1898), Manila, Ateneo de Manila University Press, 2000 ( $1^{\text {a }}$ edición publicada en New Haven, Yale University Press, 1965).

Wilson, Andrew R., Ambition and Identity. Chinese Merchant Elites in Colonial Manila, 1880-1916, Honolulu, University of Hawai'i Press, 2004.

Fecha de recepción: 16 de noviembre de 2012.

Fecha de envío de las modificaciones: 12 de junio de 2013.

Fecha de aceptación: 27 de octubre de 2013. 


\section{'Born in the country under the noble Spanish flag'. The uses of race in controlling local power in late nineteenth-century Philippines}

The article traces the use and exploitation of race and racial mixing in access to and control of local authorities in the Philippines during Spanish colonial rule, the only level of government available to native people. It analyzes how race determined the position of each individual in the colonial power pyramid-racial categories that were subsequently shaped by and enshrined in law and served to appraise privileges and exceptions. It explores the dichotomous strategies used by native elites in relation to local power during the second half of the nineteenth century. Those Principalias who did not wish to be in local government, or considered them onerous, used racial categories to shirk these responsibilities. By contrast, in the case of Principalias which were interested in occupying these local positions, the elites resorted to a defensive strategy which used the racial system to their advantage to prevent these posts being illegally usurped by Spaniards and Spanish mestizos.

Key words: Philippines; Colonialism; Elections; Local power; Indigenous. 